\title{
Criminal Behavior among the Elderly: A Look into What People Think about This Emerging Topic
}

\author{
Raqota Berger \\ California State University, Northridge, USA \\ Email:rberger@vcccd.edu
}

How to cite this paper: Berger, R. (2018) Criminal Behavior among the Elderly: A Look into What People Think about This Emerging Topic. Advances in Aging Research, 7, 1-16. https://doi.org/10.4236/aar.2018.71001

Received: January 4, 2018

Accepted: January 28, 2018

Published: January 31, 2018

Copyright $\odot 2018$ by author and Scientific Research Publishing Inc. This work is licensed under the Creative Commons Attribution International License (CC BY 4.0).

http://creativecommons.org/licenses/by/4.0/

\section{c) (i) Open Access}

\begin{abstract}
The elderly population is growing fast. With this changing demographic fact we can expect to see overall crime rates among the elderly growing right along with it. This study explored people's knowledge about elderly crime and their perceptions about elderly offenders. Survey data were collected from 229 respondents living in Southern California. Statistical analyses on the key variables revealed a number of significant group differences in regard to age $\mathrm{F}(7,221)=2.15, \mathrm{p}=0.039$, and ethnicity $\mathrm{F}(5,223)=2.60, \mathrm{p}=0.026$. The data revealed that most of the respondents believe that elderly crime is going to get worse over time (58.5\%) and that white-collar crimes were the biggest problem $(44.5 \%)$. Male respondents $(\mathrm{M}=1.80, \mathrm{SD}=3.83)$ on average knew more elderly offenders than female respondents $(\mathrm{M}=0.99, \mathrm{SD}=2.39)$. Respondents from all ages tended to believe that older people were less likely to commit street crimes but were about as likely to commit white-collar crimes as younger people. There also appears to be a pattern of increasing drug use and drug abuse among both elderly men and women. Increasing problems with criminal offending among the elderly are going to have major implications across different social systems and institutions, such as political, economic, and legal systems, corrections, rehabilitation, and medical and mental health services.
\end{abstract}

\section{Keywords}

Elderly Offenders, Perception about Elderly Crime, White-Collar Crime

\section{Introduction}

It is not a secret that the vast majority of criminal offences and convictions involve younger adults. There are many explanations given as to why younger 
people are more likely to become involved in criminal behaviors, such as having higher rates of antisocial personality, being more susceptible to peer pressure, being less invested in society and social norms, and simply being less mature and more likely to make bad life choices. Older adults are not immune to behaving in harmful ways, but they are much less likely to be involved in criminal groups (e.g., biker gangs, street gangs), are less likely to be connected to formal or informal drug cultures, and are less likely to act violently toward others (e.g., mugging people, "jumping" people, forcible rape, and so forth). With this said, there are still many things taking place culturally and demographically that merits attention in this particular area. Overall crime rates among the elderly are increasing globally and this topic should be of great interest to anyone studying, teaching, or working in the areas of criminal psychology, gerontology, sociology, criminology, or corrections.

The world's population is aging. It is estimated that by 2050 there will be around 2 billion people 60 years of age and older across the planet [1]. In the United States, the population is aging dramatically. Projections estimate that by 2020 Americans aged 55 years and older will make up around $30 \%$ of the population [2] and by the year 2050 around $21 \%$ of the American population will be 65 years of age or older [3]. If the projections hold true, and they appear to be doing just that, we can expect about 1 out every 5 Americans to be 65 years of age or older by the year 2030 [4]. With this being the case (i.e., the sheer increase in overall numbers of the elderly), we can also expect to see the overall rates of criminal offending to increase right along with it.

Researchers and scholars would be wise to pay attention to the changing patterns and trends in elderly offending as it is going to have major implications across many social systems and social institutions. There are going to be increasing costs and burdens placed on correctional facilities, mental health facilities, hospitals, the legal system, and wider economic and political systems. Academics and applied practitioners should pay attention to changing cultural conditions that may be giving rise to certain types of crimes that seem to be increasing among the elderly. Scholars and social scientists should also pay attention to interpersonal, social, political, and economic issues that may be contributing to the changes that we are currently seeing. Mental health issues are also central to so much of all of this. Access to mental health services, limited and decreasing government programs and funding, and so forth, are all factors that must be taken into consideration when making sense of this larger social problem.

This study has set out to probe further into the issue of criminal behavior among the elderly. The study looks at people's perceptions and knowledge about elderly offending and provides original information on the topic. Some central questions of importance to think about while reading this work are: What kinds of crimes are the elderly more or less likely to commit? Is criminal offending going up among the elderly? What are the patterns and trends in elderly offending? 
Are elderly men more likely to commit crimes than elderly women? What can we expect to see over time as the sheer numbers of elderly individuals continues to grow exponentially? It is the goal of this study to shed some additional light on this emerging topic of interest.

\section{Literature Review}

The overall numbers of the elderly are going to rise dramatically in the United States. By the year 2030 one-fifth of all Americans will be 65 and older, which will be twice the size that it was in the year 2000 [4] [5]. According to Barnett and Quenzel (2017), 10,000 people in America turn 65 every single day and this trend will continue until the year 2030 [3]. Research has also predicted that by the year 2050 there will be almost 84 million Americans 65 years of age and older, which will constitute approximately $21 \%$ of the U.S. population [3] [6]. Gross (2007) estimated that by the 2030 approximately one-third of all Americans will be "geriatric" [6]. With this being the case it only makes sense that crime and criminal offending among the elderly is going to become a more important topic over time. The vast numbers alone are enough to merit serious attention in these areas as there are going to be increasing real-world consequences and effects across many social systems and institutions.

One of the best ways to verify this claim is to look at the prison population. In corrections, an inmate 55 years of age is considered to be the physical peer of a 65 -year-old community-dwelling individual [6]. Most of the research stemming from corrections and the federal government clumps inmates 55 and older into the "elderly" inmate category. In 1992, the United States prison population aged 55 years and older added up to 25,613 inmates [7]. From 1995 to 2003 there was a $126 \%$ jump in the number of federal prisoners aged 65 and older, and by 2004 the prison population in America for inmates 55 and older grew from 44,200 to 69,900 [6]. According to Gross (2007), overall crime increased among the elderly from 2000 to 2004 [6], and this trend is continuing into 2018.

Even though the U.S. elderly prison population tripled from 1990 to 2001 conviction rates remained fairly stable [8]. In other words, there were other factors that played into the increase beyond just sheer increasing population numbers. Some explanations for this phenomenon include things such as mandatory sentencing, harsher sentences, and changes in policing and mandatory arrest policies [2] [8] [9]. Some researchers argue that crime rates among the elderly are actually much higher than what is officially recorded or even known about. As an example, Lindesay (1996) argued that although criminal behavior among the elderly is lower overall than it is among the young, relatively more cases go unreported/unrecorded with elderly offenders [10]. He went on to explain that police are more likely to use discretion with the elderly, are less likely to arrest the elderly, and are more likely to just give the elderly warnings [10]. Barak, Perry, and Elizur (1995) support this claim by stating in their work that the police and courts are clearly more lenient toward elderly offenders [11]. If this is 
true, then it would make sense that actual crime rates and offences among the elderly are significantly higher that what is officially known and recorded.

What kinds of crimes are the elderly more likely to commit? Different researchers have noted different things here, but there does appear to be some consensus in certain areas. Although the elderly are significantly less likely to be arrested than younger people [11], when the elderly are arrested (and convicted) there does appear to be some notable trends in what we can see taking place. Elderly offenders are more likely to be arrested for alcohol and drug-related matters [12] [13] [14] [15] than they are for most other types of crimes. Issues commonly occurring with alcohol include public intoxication and driving under the influence [14]. According to Putkonen et al. (2010), alcohol abuse is widespread among elderly offenders and is more likely than not playing some part in most types of offences that they are arrested for [12] [15]. Other types of criminal behaviors that the elderly are more likely to be arrested for involve larceny-theft, shoplifting, fraud, crimes against persons, white-collar crimes, and drug violations [2] [7] [10].

Although the elderly are less likely than younger people to violently assault or physically harm other people, there is some data that does indicate that overall rates of violence have gone up. Even though older offenders are less likely to be violent [12], some research has shown that rates of sexual offending has risen among the elderly, although overall rates are still relatively low (e.g., $4 \%$ of all elderly arrests in 2006) compared to younger offenders [13]. Risk factors for violent offending among the elderly appear to involve antisocial personality [15], a history of violence and social isolation [13], and unhealthy use of alcohol and drugs [2] [6] [7] [12] [13].

Other important factors related to criminal offending among the elderly appear to involve mental health issues. According to Aliustaoglu et al. (2011), mental illness plays an important role in criminal activities among the elderly. The researchers found delusional disorders and schizophrenia play a major role in the offending behavior of many senior citizens [1]. Gross (2007) found in his research that dementia and depression are very common mental health issues among aging offenders [6]. These findings were backed up by Carabellese et al. (2012) where they found that dementia was the most commonly occurring mental illness among elderly sex offenders [13] and by Putkonen et al. (2010) that found in their research that dementia (along with alcohol and drug abuse) was a leading presenting mental illness among violent and nonviolent elderly offenders. Others researchers have also supported these claims by finding that schizophrenia is one of the most common mental illnesses among chronic elderly offenders [12], along with other more common forms of mental illness, such as affective disorders and dementia [8] [11].

As more and more elderly offenders are placed in houses of corrections their unique needs are going to need to be met. Older inmates require much more medical care than young inmates. Older inmates also cost significantly more to 
house and take care of than younger inmates [3] [6] [9]. Older inmates also often need to be housed separately from younger inmates so they are not victimized by stronger and more violent individuals. With a major upswing in drug-related offences (including drug addiction) among the elderly [2], we are also going to have to better address the pressing need for more effective recovery and rehabilitation programs. Although criminal offending is less likely to take place among the elderly [2] [9] [10], their overall rates of incarceration are growing [1] [8] [9], so it is imperative that we are better prepared as a society to deal with the oncoming tide that we can expect to see as their projected sheer numbers in the United States swells to over 75 million within the next 15 years.

\section{General Purpose of Research}

The general purpose of this study is to try and better understand criminal behaviors among the elderly. The study has the intention of trying to better discern what kinds of crimes and criminal behaviors the elderly may be more likely to be involved with (relative to younger people). The study has also set out to capture people's perceptions about the elderly and their possible offending behaviors. The research was designed to investigate people's overall knowledge about elderly offending and to collect information to help us to be able to better make sense of wider social trends and projections. The overall goal is to capture what is going on with this growing segment of the population in regard to criminal conduct and deviant behavior.

The research also has the goal of making analytic connections to the data and to wider social trends and offending behavior. Connections will be made to the extant literatures that are intended to shed more light on this increasinglyimportant social phenomenon. Suggestions for applied practice and interventions are germane to this study. The purpose is also to show that we, as a society, must face the reality that the numbers of the elderly are growing rapidly, and that this is going to have major implications on policy, politics, economics, and legal issues. A massive amount of money is going to need to be allocated for correctional purposes, medical treatments, mental health interventions, rehabilitations, diversion programs, and so forth. The fundamental purpose of this study is to bring forth the seriousness of this increasing problem and to help people to better make sense of what is taking place in society, what people know (understand) about it, and what needs to be done to better prepare us for what is on the horizon.

\section{Methodology}

\subsection{Research Design}

For the purposes of this study, anyone aged 60 years or older was considered to be a member of the aging population. Anyone aged 60 years or older was viewed as being among the elderly, or an "older" person. This study collected data through primary survey research (November 6 through November 24, 2017) 
across Los Angeles and Ventura counties. This was an independently conducted study and was not funded or regulated by any institution. There are no conflicts of interest with this study. The data was collected in a nonrandom fashion whereby respondents were recruited on their willingness to fill out the survey. Consent was given by the respondent's willingness to fill out the survey. As the instrument does not take very long to fill out, there was no compensation provided for participation. Respondents were recruited from local shopping malls, businesses, restaurants/coffee shops, colleges, universities, and residential neighborhoods. The only requirement for inclusion in the study was the respondents were willing to fill out the questionnaire and that they were at least 18 years of age. No minors were included in the study. The survey consisted of several questions asking about basic demographic variables (e.g., gender, age, and ethnicity). These specific types of variables are important for making distinct comparisons across social groups and for making any inferences about group differences. The survey asked respondents to provide information regarding their knowledge of criminal behavior among elderly people that they personally know. The survey collected information on the types of crimes that have been committed, according to the respondents, and what types of crimes they believe the elderly are the most likely to engage in. The survey also consisted of 5-point Likert-type scale items designed to provide information about the respondents general feelings about older individuals and the types of crimes they are, or are not, likely to commit (e.g., street crimes, white-collar crimes) relative to younger people. The scales range from 1 to 5 , where 1 meant "Strongly Disagree" and 5 meant "Strongly Agree". The number 3 was considered a neutral response with no leaning in one directions or another. The instrument also asked the respondents about how many elderly offenders they know personally and what their thoughts are regarding increasing elderly crime rates over time.

\subsection{Research Participants}

The study consisted of 229 respondents that reside in the Southern California region. The study included 130 women, 97 men, and 2 respondents that identified as "other." The age range of the respondents was from 18 to 84 . The largest segment of respondents were in their 20's (45.9\%), followed by respondents in their 60 's $(15.3 \%)$, respondents $18-19$ (10\%), respondents in their 40 's $(9.2 \%)$, and respondents in their 30's and 50's each made up 7.4\% of the total sample. Respondents in their 70's and 80 's respectively made up $3.9 \%$ and $0.9 \%$ of the overall sample. No one under the age of 18 was given the questionnaire to fill out. Respondents over the age of 60 made up $20 \%$ of the sample. Hispanics made up the largest percentage of the respondents (65.9\%), followed by Whites (18.8\%), Blacks (7.0\%), Asian/Pacific Islanders (5.2\%), Middle Easterners (1.7\%), and Other/Mixed (1.3\%). This sample is skewed somewhat toward Hispanics due to the fact that most of the surveys were completed in the Los Angeles area. Outside of this, the order of decreasing percentages is reflective of the larger ethnic make-up in Southern California. The study did not have any respondents 
that identified as Native American.

\subsection{Data Analysis}

The data were primarily computed and analyzed through the use of the statistical software SPSS 24. Discrete variables were coded as needed so that various statistical analyses could be performed. The continuous level variables were placed directly into the database for appropriate analyses. Descriptive statistics were employed across most analyses involving the categorical variables. Multiple correlations were used to detect any significant associations between key variables and scale items (Pearson's r, gamma, Spearman's rho). Multiple comparisons and significance tests were run across appropriate variables and scale items (median test, Kruskal-Wallis, Somer's d, Mann-Whitney U). Chi-square analyses were also run on appropriate categorical variables. The t-test for independent samples was used for analysis of gender responses and any meaningful statistical differences between these two groups. The one-way ANOVA was utilized to detect any significant differences between ethnic groups and clustered age groups. Post hoc tests were run to help decipher meaningful group differences (Bonferroni, Tukey, and LSD). A power calculation revealed that a sufficient sample size for this study and design was 196 (95\% C. I.). The sample size collected $(\mathrm{N}=229)$ surpassed this number and meets the requirements for adequately detecting differences between groups. The level of statistical significance was set a 0.05 for all analyses. The direction of significance was two-tailed for the range statistical analyses conducted across the various tests.

The survey items that asked about types crimes were bunched together according to common crime categories (e.g., fraud and white-collar crime; rape and sexual assault; etc.). This was necessary to make sure that common categories were derived and that there were not too many disconnected and non-analyzable categories (e.g., driving under the influence of alcohol and driving without a license were both categorized as driving violations). If any questionnaire item was left blank it was not included in any analysis pertaining to that specific variable or item. None of the surveys had to be discarded for clearly fabricated responses or for responses that were unclear or nonsensical. All 229 questionnaires that were filled out were deemed to be valid and useful for the purposes of this investigation. Some respondents did express concern about what a couple of the questions were asking about in regard to when the crimes were committed (i.e., before or after the offender was 60 years of age). This needed to be clarified and may have altered some of the responses provided. Outside of this minor issue, the respondents appeared to enjoy filling out the questionnaire and seemed to understand what its purpose was.

\section{Results}

\subsection{Descriptive Statistics}

When asked if older people are more likely to commit crimes than younger 
people the respondents tended to be somewhat neutral in their position or they leaned slightly toward disagreement with this statement $(\mathrm{M}=2.35, \mathrm{SD}=1.10$; women $=2.40$, men $=2.27$ ). Some respondent leaned further in one direction or the other (e.g., strong disagreement or strong agreement), but most were closer to the middle when it came to this particular statement. When asked to provide their thoughts on older people and committing white-collar crimes the respondents generally leaned further in agreement $(\mathrm{M}=3.78, \mathrm{SD}=1.11$; women $=3.66$, men $=3.92$ ), but there was still a slight overall leaning toward neutrality. The respondents were more likely to believe that younger people are more likely to engage in street crime than older people $(\mathrm{M}=4.05, \mathrm{SD}=1.21$; women $=4.18$, men $=3.90$ ). There was a general pattern in the data that revealed that both younger and older people tend to believe that younger people are more likely to be involved in street crime (32\% agreed with this, $47 \%$ strongly agreed with this). White-collar crime showed a different pattern, whereby both young and older people felt that young and old people were about equally likely to commit such crimes, with a slight leaning more toward older people offending in these types of ways (22.3\% neutral, $33.2 \%$ agreed, $31 \%$ strongly agreeing).

When asked how many older people they personally know that have committed crimes the overall average was 1.30. Women appeared to know fewer offenders $(M=0.99, S D=2.39)$ than the male respondents $(M=1.80, S D=3.83)$. That is, the female respondents tended to know around 1 offender personally, whereas the male respondents tended to know approximately 2 offenders personally. When asked if they believe that elderly offending is going to increase over time the majority of respondents felt that it will (Yes $=58.5 \%$, No $=41.5 \%$ ). Both younger and older respondents tended to lean in the direction that elder crime is going to increase over time as their overall numbers increase.

\subsection{Types of Crimes}

A major purpose of this study was to collect data on the types of crimes the elderly are committing. Twenty-nine percent of the sample stated that they personally know an elderly man that has committed one or more crimes. Only $13.5 \%$ of the sample stated that they personally know an elderly woman that has committed any type of crime. In descending order, the most common types of crimes committed by elderly individuals as reported by the respondents are white-collar crimes $(n=102,44.5 \%)$, theft/stealing $(n=43,18.8 \%)$, sex-related crimes $(\mathrm{n}=18,7.9 \%)$, driving-related crimes $(\mathrm{n}=17,7.4 \%)$, violent crimes/assault/murder $(\mathrm{n}=12,5.2 \%)$, drugs/alcohol $(\mathrm{n}=10,4.4 \%)$, domestic violence/abuse $(n=9,3.9 \%)$, and robbery/property crimes $(n=8,3.5 \%)$. Crimes that fell under $1 \%$ included kidnapping, child support, and suicide. Six respondents $(2.6 \%)$ did not respond to this particular question. The respondents clearly felt that white-collar crimes were the most common among the elderly. This was particularly true for male offenders. The respondents showed a slightly different set of responses for elderly female offenders. Here the respondents knew about 
as many elderly women that have been arrested for (or have committed) drug or alcohol-related crimes (25\%) as for any type of white-collar crime (22\%).

\subsection{Parametric Analyses}

Independent samples means tests did not reveal any significant differences between women and men in regard to their thoughts about elderly individuals committing more crimes than younger individuals $(\mathrm{t}=0.882$, sig. $=0.379)$, committing more white-collar crimes $(t=1.74$, sig. $=0.084)$, or being more or less likely than younger people to commit street crimes $(t=1.70$, sig. $=0.092)$. An analysis of variance test, along with various post hoc comparisons, did reveal some group differences in regard to age and their thoughts on elderly crime. Older respondents (40 and older) were more likely to believe that older people are more likely to commit white-collar crimes than younger people $F(7,221)=$ $2.15, \mathrm{p}=0.039$. Older respondents were also significantly more likely to know an older offender than younger respondents $F(7,221)=3.27, p=0.003$. In regard to white-collar crime, younger respondents (under 30) felt that older people were more likely to commit white-collars crimes than younger people. This younger age group differed significantly in their opinions than older respondents in their 60 's (LSD sig. $=0.004)$ and 70's (LSD sig. $=0.05$ ) that believed younger people were as likely to commit white-collar crimes as older people.

Post hoc comparisons also revealed that respondents in their 80 's were significantly more likely to believe that younger people are much more likely to commit street crimes than older people. Compared to respondents under 30 they had significantly different beliefs about street crimes and age of offenders (LSD sig. = 0.047). Post hoc comparisons also revealed significant group differences between multiple groups in regard to how many older people they know personally that have committed crimes. Those respondents between 18 - 19 and 20 - 29 tended to have significantly different firsthand knowledge of this particular question compared to each other (Tukey's HSD sig. $=0.007$; Bonferroni sig. $=0.008$ ) and when compared to older respondents. Respondents in their 50's, 60's, and 70's tended to personally know more elderly offenders on average than respondents between 18 and 39. For example, significant LSD differences between means included respondents in their 20's and 50's (0.007), 20's and 70's (0.031), 18 - 19 and 60's (0.002), 30's and 50's (0.026), and 30's and 70's (0.05) all significantly differing in this area. Other post hoc comparisons revealed significant group differences but they all showed the same general pattern-older respondents tended to personally know more elderly offenders than younger respondents.

Tests across the various ethnic groups in the study only revealed one significant finding. Groups did not feel the same way about the statement that older people were as likely to commit crimes as younger people, $F(5,223)=2.60, \mathrm{p}=$ 0.026 . Black respondents had a higher than average response rate when it came to knowing older offenders. Thus, Black respondents were less likely than other groups to believe that older people were less likely to commit crimes than 
younger people. Tukey's HSD revealed several significant differences compared to Hispanics (0.017), Middle Easterners (0.013), and Whites (0.044). LSD comparisons also found differences between Black respondents and Hispanics (0.001) and Whites (0.004). Bonferroni comparisons also revealed a significant difference between Black and Hispanic respondents (0.02) when it came to this particular question. Black respondents were also more likely than Hispanic (LSD sig. $=0.012)$, White respondents $($ LSD sig. $=0.037)$, and Asian respondents (LSD sig. $=0.041)$ to believe that older people are about as likely to commit street crimes as younger people. Middle Eastern respondents had the lowest rates when it came to personally knowing older offenders. They differed from just about all other groups, such as Hispanic (LSD sig. $=0.02)$, White (LSD sig. $=0.027)$, and Asian (LSD sig. $=0.021)$.

\subsection{Correlational Analyses}

A single Pearson's correlation was significant and it had to do with respondent's feelings about older people being more likely to commit crimes than younger people and older people being more likely to commit white-collar crimes $(r=$ $2.44, p=0.000$ ). Kendall's tau analysis revealed significant correlations between respondent's feelings about younger people being more likely to commit street crimes and older people being more likely to commit crimes in general than younger people $\left(\mathrm{r}_{\mathrm{v}}=-0.12, \mathrm{p}=0.033\right)$ and respondents feelings about older people being more likely to commit white-collar crimes and older people being more likely to commit crimes in general than younger people $\left(\mathrm{r}_{\mathrm{v}}=0.17, \mathrm{p}=\right.$ 0.003). Spearman's correlational analysis found significant correlations between respondent's feelings about older people being more likely to commit crimes than younger people and older people being more likely to commit white-collar crimes $\left(r_{s}=0.19, p=0.004\right)$ and respondent's beliefs that older people are more likely to commit crimes than younger people and younger people are more likely to commit street crimes than older people $\left(\mathrm{r}_{\mathrm{s}}=-0.14, \mathrm{p}=0.041\right)$. Somer's $\mathrm{d}$ revealed a significant association whereby respondent's showed a pattern of feeling that younger people were more likely to commit street crimes and older people were less likely to commit crimes in general $(\mathrm{d}=-0.12, \mathrm{p}=0.049)$. Gamma measures revealed a significant association between the same variables found by Somer's analysis $(\mathrm{g}=-0.17, \mathrm{p}=0.04)$. Both Gamma and Somer's $\mathrm{d}$ analyses found significant associations between respondent's beliefs that older people are more likely to commit white-collar crimes and older people being more likely to commit crimes in general $(\mathrm{g}=0.25, \mathrm{p}=0.006 ; \mathrm{d}=0.17, \mathrm{p}=0.006)$.

\subsection{Nonparametric Analyses}

Although there were a number of analyses that failed to reject the null hypotheses in regard to the discrete levels of measurement, there were also several significant findings worthy of attention. A chi-square analysis resulted in a significant finding in regard to how the various ethnic groups felt about older people and 
committing crimes and younger people committing street crimes, $\mathrm{X}^{2}(20)=$ $46.16, \mathrm{p}=0.001$. In general most ethnic group felt that younger people were more likely to commit street crimes (although Black respondents did not feel this way) and there were several differences in regard to how they felt about crime in general between older and younger people. Hispanics and Whites were more likely to feel that younger people were more prone toward street crimes, but Asian and Middle Eastern respondents felt more neutral on this matter. Black respondent's felt that older people were as apt to commit street crimes as younger people.

The Kruskall-Wallis test revealed significant differences across age groups in regard to how many older people the respondent's know personally that have committed any crimes (sig. $=0.009$ ). In comparison to younger respondents, it appears that older respondents were more likely to know older people that have committed some types of criminal offence. This is in line with what was discovered in some of the parametric analyses described above. The Kruskal-Wallis test also found significant results in regard to differences across ethnic groups and their views about older people being more likely to commit crimes in general (sig. $=0.019)$. As covered earlier, certain ethnic groups seem to believe that older people are just as likely to commit crimes as younger people (e.g., Black), whereas other ethnic groups believe that they are not (e.g., Middle Eastern, Asian). The Median test revealed a single significant difference between ethnic groups and their beliefs about older people being more likely to commit crimes than younger people $($ sig. $=0.019$ ). The median split across the various ethnic groups were not the same and some groups felt that younger people were more likely to commit crimes than older people (e.g., Middle Eastern, Hispanic, and White), whereas other felt that they were just as likely (e.g., Black). The other nonparametric tests employed did not reveal any significant group differences across the discrete study variables (e.g., Mann-Whitney U).

\section{General Discussion}

There were a number of interesting findings produced by this study. The majority of the respondents did feel that elderly crime is going to become more of a social problem over time. This is something that seems to be in line with the projections set forth by many other researchers and government agencies [1] [2] [6] [9] [10]. When asked about what types of crimes the respondents expect to get worse over time, in regard to older offenders, there were some pretty clear patterns in the responses. Almost every single respondent mentioned some type of white-collar crime (e.g., tax evasion, fraud, insurance fraud, embezzlement) as being something that they expect to see taking place more and more among the elderly population. This makes sense when one thinks about the positions that many older Americans are in. Many of their professional roles place them in positions where they have access to other people's accounts and personal information. They are also often working in professions where they have access to money 
or the means of funneling money into certain accounts. Younger people do not typically hold positions of power and do not typically have the access and means that a more seasoned professional might.

White-collar crime refers to any illegal acts committed within the scope of one's profession or career [16]. That is, white-collar crimes are put into action through the various roles and statuses that older people often occupy (e.g., president, executive, lawyer, accountant, financial management, etc.). This could potentially be connected to relevant theories of differential association whereby people are exposed to attitudes favorable to criminal acts and they become more likely to offend themselves through observational and social learning [16] [17]. When people are around others that are committing crimes they become more likely themselves to also become involved at some point. Another major pattern detected in the collected data in this study has to do with drug use and drug violation among the elderly. Outside of white-collar crime, drug use and drug violations were mentioned more than any other type of crime. Based on the data collected it seems pretty clear that people are becoming more concerned about drug use, abuse, and addiction among the aging population. This fits in well with other research that has shown that drug use and arrests have been steadily climbing over the years [2] [6] [14]. This is another problem area that demands much more attention.

It was also interesting to see how men, on average knew about twice as many older offenders as women. This makes one wonder about things as differential association, exposure, and proximity theories. Are older offenders more likely to discuss or expose their criminal behaviors to men than they are to women? Are women less likely to associate with older offenders? Or are men just more likely to recognize criminal behaviors and label them as such? There were some other notable differences in regard to age and ethnicity. Older people were clearly more likely to think that older people were much less likely to be involved in street crimes. Older people were also as likely as younger people to believe that older offenders are just as likely to be involved in some type of white-collar crime as younger people are. All ages felt that older people were less likely to be violent than younger people. Black respondents had the overall highest numbers when it came to personally knowing older criminal offenders and they were also the least likely to feel that older people were less likely to commit crimes than younger people. Other groups, such as Middle Eastern and Asian, tended to believe that older people were generally much less likely to commit crimes (of any type) than younger people. Hispanic and White respondents were more mixed in their attitudes and beliefs, but they still showed a general pattern in their belief that older people are less likely to commit street crimes and are as likely as young people to commit other types of crimes (e.g., fraud, driving violations, embezzlement, etc.).

For the vast majority of the respondents when they personally knew an older offender it was usually an older man. When the respondents did know an older 
women that was a criminal offender they typically also knew one or more older men that were also criminal offenders. In most cases, when they did know of an elderly female offender it was not connected to the male offender mentioned. When the respondents did personally know an older female offender the crimes usually revolved around theft/stealing and drug offences. The older male offenders were more likely to be involved in violent offences. These findings hold with what has been found in prior studies looking at gendered behavior and criminality [2] [7] [18]. Older men and women do appear to differ in their rates and types of offending. This is something else that merits further research and will clearly have real implications on future policies and funding budgets (e.g., correctional facilities, mental health hospitals, and medical treatments).

The findings of the study reveal some important things that should be given further attention from political and social leaders. The population of the United States is aging [3] [5]. The population of the world is aging fast [1] [11] and we better be ready for the consequences of this. Rates of elderly offending are going to continue to rise as their sheer numbers continue to swell and there will be real implications and costs associated with housing elderly offenders [6] [18], treating them for medical and mental illnesses [3] [8] [9], and providing diversionary and community-based services to elderly offenders [4] [18]. White-collar crime is going to continue to be a major problem among the elderly, and will probably even become significantly worse over time.

We also have to pay much more attention to another imploding problem sweeping across the nation-prescription drug abuse and addiction. More elderly individuals are using prescription drugs than ever before and the problems associated with this go in all directions. It appears that rates of elderly offending in this area are also on the rise [2] [6] [18] [19] and more and more aging individuals are being brought into emergency rooms for harmful drug interactions and overdosing. There is also a growing problem with older people buying and selling prescription drugs illegally. These are just some of the growing problems that deserve further attention from academics, political leaders, and business leaders alike.

\subsection{Limitations of Study}

As with all research, we realize that certain things could have been better after we have already gone through the process. Some limitations of the study involve the demographics. All of the respondents are living in the Southern California region. There may be important differences in regard to people's beliefs and perceptions of elderly crime across the nation (e.g., Midwest, Southern, Northeastern states). To note, a good portion of the respondents are not from Southern California (e.g., some are immigrants from other countries, some moved here from other states) but they are all living in the Los Angeles area at this time. This may have altered their views and opinions about the topic at hand. Another limitation revolves around the fact that there were only 11 respondents 
in their 70's through 80's. Collecting more data on this older demographic would help to shed some more light on this topic in regard to how some of the older members of society feel about these issues and social problems. The study also simply relied on self-reporting and placed faith that respondents would be able to think deeply enough about the topic without too much interference from the researcher. It was learned after the collection of most of the data that some respondents were interpreting a couple of the questions differently (e.g., whether the crimes committed happened before or after the offenders turned 60 years of age). This is something that would need to be better clarified in a future study. Researcher has shown time and time again that people are not always completely objective or insightful when it comes to their own attitudes and beliefs about certain social issues that may be deemed offensive by certain social groups. As with all research, the study had its limitations and areas that could have been refined a bit more. Overall, though, it is believed that the study ultimately produced useful and informative results.

\subsection{Contributions and Potential Future Research}

The current study has shed some additional light on a global issue that is going to demand much more attention from the world's economic and political leaders. The world's population is aging. In fact the elderly are the fastest growing segment of the world's population, and this trend is only going to continue over time. The population demographics in the United States aged 65 years and over is around $20 \%$, and it is only going to grow over time. We are seeing very similar population shifts in many other nations around the world (e.g., Japan, China, Italy, Greece, Finland) and we can expect to see this trend taking place in many more nations as the world modernizes and people live even longer than they already are. The study has taken an additional look into an emerging social problem that we can expect to become even more significant over time. The population of the United States is aging. The population around the world is aging. It only stands to reason that crime rates among the elderly are going to increase over time as well. If nothing else, it is a sheer numbers game. As we begin to see more and more people living past 60 we can expect to see certain things taking place more often (e.g., white-collar crimes, driving violations, drug offences, etc.).

The findings from this study demonstrate that there is a perceived problem with elderly offending and that most people believe that crime among the elderly is going to increase over time. The findings suggest that more research and attention needs to be given to areas particularly related to white-collar crime and substance abuse. Future research should pay close attention to monetary-based crimes, such as fraud. According to data collected this appears to be one of the most common offences among the elderly. In addition, based on the findings from the current study it is also recommended that future research pays special attention to the growing problem with prescription drug abuse and addiction. This is another major problem area that appears to be getting worse over time. 
There needs to be far more research across all areas involved - retirement issues, medical issues, rehabilitation and mental health services, criminal justice, law enforcement, social and community programs, outreach, education, and so forth. Leaders around the world would be wise to pay close attention to this. There will be major implications on legal systems, corrections, policy, medical and mental health treatment, etc. There will also be real implications on people's lives, families, and local communities. The research in this expanding area of importance is just beginning.

\section{Conclusion}

In the United States, the "baby boomers" and "generation $x$ " are all getting older. The baby boomers are all moving into their 60's and 70's. This is a massive age cohort. Within the next 10 years, generation $\mathrm{x}$ will be moving into their 60 's. With this being the case, the population of the United States is going to continue to get older and we are going to see some significant changes taking place socially, culturally, and economically. We are also going to see a surge in crimes committed by people 60 years of age and older. It is not that older people are going to become more deviant. It is simply a function of math and percentages. As more people get older, we are going to see more crimes being committed overall by older people. Emerging crime problems will revolve heavily around drug and alcohol-type crimes, driving offences, physical and sexual assault, theft, and especially white-collar crimes. We will also need to pay much more attention to the escalating problems associated with prescription drug abuse and misuse. This study has brought additional attention to this growing social issue. Researchers and leaders from around the world would be wise to pay attention to, and be prepared for, the upcoming wave of aging offenders.

\section{References}

[1] Aliustaoglu, F.S., Ozdemir, M., Ince, H., Yazici, Y.A., Ince, N. and Oral, G. (2011) Criminal Activities of the Elderly in Turkey during the Years 2000-2005. Archives of Gerontology and Geriatrics, 53, 267-270.

https://doi.org/10.1016/j.archger.2010.11.028

[2] Feldmeyer, B. and Steffensmeier, D. (2007) Elder Crime: Patterns and Current Trends, 1980-2004. Research on Aging, 29, 297-322. https://doi.org/10.1177/0164027507300802

[3] Barnett, J.E. and Quenzel, A.P. (2017) Innovating to Meet the Needs of Our Aging Population. Practice Innovations, 2, 126-139. https://doi.org/10.1037/pri0000049

[4] Ross, M. and Schryer, E. (2015) Outsourcing Memory in Response to an Aging Population. Perspectives on Psychological Science, 10, 716-720. https://doi.org/10.1177/1745691615605258

[5] Nelson, T.D. (2005) Ageism: Prejudice against Our Feared Future Self. Journal of Social Issues, 61, 207-221. https://doi.org/10.1111/j.1540-4560.2005.00402.x

[6] Gross, B. (2007) Elderly Offenders: Implications for Corrections Personnel. The Forensic Examiner, 56-61. 
[7] Aday, R.H. (1994) Aging Is Prison: A Case Study of New Elderly Offenders. International Journal of Offender Therapy and Comparative Criminology, 38, 79-91. https://doi.org/10.1177/0306624X9403800108

[8] Yorston, G.A. and Taylor, P.J. (2006) Commentary: Older Offenders-No Place to Go? Journal of the American Academy of Psychiatry and the Law, 34, 333-337.

[9] Davoren, M., Fitzpatrick, M., Caddow, F., Caddow, M., O’Neill, C., O’Neill, H. and Kennedy, H.G. (2015) Older Men and Older Women Remand Prisoners: Mental Illness, Physical Illness, Offending Patterns and Needs. International Psychogeriatrics, 27, 747-755. https://doi.org/10.1017/S1041610214002348

[10] Lindesay, J. (1996) Elderly People and Crime. Reviews in Clinical Gerontology, 6, 199-204. https://doi.org/10.1017/S0959259800004664

[11] Borak, Y., Perry, T. and Elizur, A. (1995) Elderly Criminals: A Study of the First Criminal Offence in Old Age. International Journal of Geriatric Psychiatry, 10, 511-516. https://doi.org/10.1002/gps.930100611

[12] Wong, M.T., Lumsden, J., Fenton, G.W. and Fenwick, P.B. (1995) Elderly Offenders in a Maximum Security Mental Hospital. Aggressive Behavior, 21, 321-324. https://doi.org/10.1002/1098-2337(1995)21:5<321::AID-AB2480210502>3.0.CO;2-5

[13] Carabellese, F., Candelli, C., Vinci, F., Tamma, M. and Catanesi, R. (2012) Elderly Sexual Offenders: Two Unusual Cases. Journal of Forensic Sciences, 57, 1381-1383. https://doi.org/10.1111/j.1556-4029.2012.02129.x

[14] Petersen, D. (1988) Substance Abuse, Criminal Behavior, and Older People. Journal of the American Society on Aging, 12, 63-67.

[15] Putkonen, H., Weizmann-Henelius, G., Repo-Tiihonen, E., Lindberg, N., Saarela, T., Eronen, M. and Hakkanen-Nyholm, H. (2010) Journal of Forensic Sciences, 55, 1552-1556. https://doi.org/10.1111/j.1556-4029.2010.01488.x

[16] Schaefer, R.T. (2015) Sociology: A Brief Introduction. 11th Edition, McGraw-Hill, New York.

[17] Franzoi, S.L. (2016) Social Psychology. 7th Edition, BVT Publishing, Redding, CA.

[18] Clear, T.R., Reisig, M.D., Petrosino, C. and Cole, G.F. (2017) American Corrections: In Brief. 3rd Edition, Cengage Learning, Boston, MA.

[19] Siegel, L. and Bartollas, C. (2016) Corrections Today. 3rd Edition, Cengage Learning, Boston, MA. 